\title{
Repression of yeast Ste12 transcription factor by direct binding of unphosphorylated Kss1 MAPK and its regulation by the Ste7 MEK
}

\author{
Lee Bardwell, Jeanette G. Cook, ${ }^{1}$ Deepak Voora, Daniel M. Baggott, Anthony R. Martinez, \\ and Jeremy Thomer \\ Department of Molecular and Cell Biology, Division of Biochemistry and Molecular Biology, University of California, \\ Berkeley, California 94720 USA
}

The mitogen-activated protein kinase (MAPK) Kssl has a dual role in regulating filamentous (invasive) growth of the yeast Saccharomyces cerevisiae. The stimulatory function of Kssl requires both its catalytic activity and its activation by the MAPK/ERK kinase (MEK) Ste7; in contrast, the inhibitory function of Kssl requires neither. This study examines the mechanism by which Kssl inhibits invasive growth, and how Ste7 action overcomes this inhibition. We found that unphosphorylated Kssl binds directly to the transcription factor Stel2, that this binding is necessary for Kss1-mediated repression of Ste12, and that Ste7-mediated phosphorylation of Kssl weakens Kssl-Stel2 interaction and relieves Kssl-mediated repression. Relative to Kss1, the MAPK Fus3 binds less strongly to Ste12 and is correspondingly a weaker inhibitor of invasive growth. Analysis of Kss1 mutants indicated that the activation loop of Kssl controls binding to Stel2. Potent repression of a transcription factor by its physical interaction with the unactivated isoform of a protein kinase, and relief of this repression by activation of the kinase, is a novel mechanism for signal-dependent regulation of gene expression.

[Key Words: Protein-protein interaction; signal transduction; gene regulation; devel opmental control; invasive growth]

Received June 8, 1998; revised version accepted July 24, 1998.

Commitment of a cell to a developmental fate entails a change in the pattern of gene expression. In many instances, this gene regulation is controlled by signaltransduction pathways that affect the phosphorylation of transcription factors (or their associated proteins) by protein kinases (for review, see Karin 1994; Hill and Treisman 1995; Treisman 1996). Phosphorylation can control the localization or sequestration of many transcription factors, as shown for yeast Swi5, Drosophila dorsal and yan, SV40 large T antigen, and vertebrate N F-кB, NFAT, STATs, and SMADs (for review, see Hill and Treisman 1995; Vandromme et al. 1996; Heldin et al. 1997). Phosphorylation by protein kinases can also influence the DNA-binding activity of transcription factors. For example, DNA-binding of Elk-1 is stimulated by the Erk and Jnk mitogen-activated protein kinases (MAPKs), whereas DNA-binding of c-Jun is inhibited by CKII (for review, see Treisman 1996). The transactivation poten-

\footnotetext{
${ }^{1}$ Present address: Department of Genetics, Duke University Medical Center, Durham, North Carolina 27710 USA.

${ }^{2}$ Corresponding author.

E-MAIL jeremy@socrates.berkeley.edu: FAX (510) 643-5035.
}

tial of transcription factors can also be regulated independently of DNA binding. For example, protein kinase A (PKA)-mediated phosphorylation of CREB, as well as Jnk-mediated phosphorylation of c-Jun, stimulates the binding of the coactivators CREB-binding protein (CBP) and P300 (for review, see Goldman et al. 1997), and Cdkmediated phosphorylation of $\mathrm{Rb}$ leads to dissociation of this repressor from E2F (for review, see DePinho 1998). Finally, protein kinases can regulate transcription factor stability (Clevers and van de Wetering 1997). In all of these cases, the catal ytic (phosphotransferase) activity of the protein kinase involved is an indispensable component of its regulatory action.

Recent studies of invasive growth in the yeast Saccharomyces cerevisi ae have reveal ed an unexpected and previously unknown mode of protein kinase-mediated regulation. In this developmental response, the principal regulatory role of the MAPK Kssl is as an inhibitor, and this function does not require its catalytic activity (Cook et al. 1997; Madhani et al. 1997). Kss1 was first characterized as a component of the signaling cascade required for response to mating pheromone (for review, see Bardwell et al. 1994b; Leberer et al. 1997). In this path- 
way, pheromone-receptor binding leads to activation of a MAPK module. Stell (a MAPK kinase kinase or MEKK) phosphorylates and activates Ste7 (a MAPK kinase or MEK); Ste7, in turn, phosphorylates and activates two MAPKs, Kss1 and Fus3 (Errede et al. 1993; N eiman and Herskowitz 1994; Bardwell et al. 1996). Kss1 and Fus3 then stimulate, directly or indirectly, the transcription factor, Ste12, permitting expression of a battery of genes invol ved in the mating process (Erdman et al. 1998). Deletion (or mutation that destroys the catalytic activity) of any tier of this MAPK cascade-STE11, STE7, or both KSS1 and FUS3-abolishes pheromone-induced transcription and results in sterility (Rhodes et al. 1990; Elion et al. 1991; Cairns et al. 1992; Ma et al. 1995).

Invasive (filamentous) growth is a distinct developmental option available to both haploids and diploids. Cells undergoing this process become el ongated; alter their cell cycle, budding pattern, and adhesiveness; and acquire the capacity to penetrate beneath the surface of an agar plate (Gimeno et al. 1992; Kron et al. 1994; Roberts and Fink 1994). Invasive growth is regulated by a signaling network containing at least two parallel branches (C ook et al. 1997; Lo et al. 1997; Chandarlapaty and Errede 1998). It has been shown (Liu et al. 1993; Roberts and Fink 1994) that one branch utilizes proteins that are also components of the pheromone response pathway, including the protein kinases, Ste20 [a p21-activated kinase (PAK) homolog], Stell, Ste7, and the Stel2 transcription factor. Ste12 cooperates with the Tecl transcription factor to regulate genes specific for invasi ve growth (Lal oux et al. 1994; Gavrias et al. 1996; Baur et al. 1997; Madhani and Fink 1997). Upstream components of the invasive growth signaling network, including Mep2 (an ammonium permease; Lorenz and Heitman 1998), G pa2 (a $G \alpha$ subunit; Kübler et al. 1997), Bmh1 and Bmh2 (14-3-3 proteins; Roberts et al. 1997), and Ras2 and Cdc42 (two small GTPases; Gimeno et al. 1992; Mösch et al. 1996), are coupled to downstream branches by mechanisms that are not completely understood.

Until recently, the MAPK target of Ste7 in invasive growth was unknown. Because deletion of either KSS1 or FU S3 (or both) only moderately affected invasive growth, whereas deletion of STE7 caused a substantial reduction in invasi veness (Liu et al. 1993; Roberts and Fink 1994), it was proposed that Ste7 has substrates other than Kss1 and Fus3, perhaps even non-MAPK targets (for review, see Hunter and Plowman 1997). This conundrum was resolved by experiments showing that invasive growth could be restored to a strain lacking STE7 by also deleting KSS1 (Cook et al. 1997; Madhani et al. 1997). This result established that Kssl acts to inhibit invasive growth, and suggested that Ste7 functions, in response to appropriate upstream signal s, to all eviate Kss1-mediated inhibition. Fus3 al so inhibits invasive growth, but is less potent, and only functions in haploid cells (Cook et al. 1997). Kss1 also has a stimulatory role in invasive growth that (in contrast to its inhibitory role) requi res its protein kinase activity (Cook et al. 1997; Madhani et al. 1997).
Here, we demonstrate that Kssl-mediated inhibition of invasive growth operates at the level of transcription, characterize the mechanism of this transcriptional repression, and examine its regulation by upstream signals.

\section{Results}

Ste7-mediated phosphorylation is necessary and sufficient to relieve Kssl-mediated inhibition of invasive growth

Deletion of STE7 substantially reduces invasive growth (Liu et al. 1993; Roberts and Fink 1994). We found that neither an unactivatable ste7 allele (T363V; N eiman and Herskowitz 1994) nor a catalytically inactive allele (K220R; Cairns et al. 1992) could restore invasive growth to ste7 $\Delta$ cells (data not shown). Thus, both phosphorylation and activation of Ste7 (presumably by Stel1) and the subsequent phosphorylation of downstream substrates by Ste7 are required for invasive growth. Ste7 is required for invasive growth only if Kssl is al so present, implicating Kssl as the principal target of Ste7 in this process (Cook et al. 1997; Madhani et al. 1997). To examine how Kssl-mediated inhibition of invasive growth is relieved by Ste7 function, a series of kssl alleles (Fig. $1 \mathrm{~A}$, a) was introduced, on low-copy (CEN) vectors, into a derivative of $\Sigma 1278 \mathrm{~b}$ lacking both $\mathrm{Kssl}$ and Fus3, strain JCY130 (MATa STE7 ${ }^{+}$kssl $\Delta$ fus3 $\Delta$ ). The biochemical and genetic properties of these Kssl mutants with re spect to pheromone response have been extensively characterized ( $M$ a et al. 1995; Bardwell et al. 1996). Two of these mutants, $\mathrm{KSSl}_{\mathrm{Y} 24 \mathrm{~F}}$ and $\mathrm{KSSl}_{\mathrm{K} 42 \mathrm{R}} \mathrm{Q} 45 \mathrm{P}$, contain substitutions in conserved subdomains involved in ATP binding and are catalytically inactive, but are phosphorylated by Ste7 to the same extent as wild-type Kssl (M a et al. 1995; Bardwell et al . 1996; see also Fig. 1C). The other three mutants are al tered in the target site (183-Thr-GluTyr-185) for Ste7-mediated phosphorylation: $\mathrm{Kss}_{\mathrm{T} 183 \mathrm{~A}}$, which can be phosphorylated only on $\mathrm{Y} 185 ; \mathrm{KsSl}_{\mathrm{Y} 185 \mathrm{~F}}$, which can be phosphorylated only on T183; and KssI ${ }_{\mathrm{AEF}}$ (containing both substitutions), which cannot be phosphorylated by Ste7 (M a et al . 1995). These three mutants are unactivatable, and consequently lack detectable protein kinase activity (M a et al. 1995; Bardwell et al . 1996). N evertheless, both classes of inactive mutants repress invasive growth when Ste7 is absent (Cook et al. 1997).

Strain JCY 130 expressing each mutant, normal Kssl, or no Kss1 at all, grew equally vigorously (Fig. 1A, b). Only wild-type Kssl supported detectable mating (Fig. $1 \mathrm{~A}, \mathrm{c}$ ), as observed previously in $\mathrm{kss} 1 \Delta$ fus3 $3 \Delta$ strains of the S288C and W303 lineages (Elion et al. 1991; Ma et al. 1995). In the standard bioassay for invasive growth (Fig. $1 \mathrm{~A}, \mathrm{~d}$ ), neither the absence of Kssl nor the presence of wild-type Kss1 prevented invasive growth. In contrast, none of the three unactivatable mutants $\left(\mathrm{KSSl}_{\mathrm{T} 183 \mathrm{~A}}\right.$, $\mathrm{KSSl}_{\mathrm{Y} 185 \mathrm{~F}}$, and $\mathrm{KSSl_{ \textrm {AEF } }}$ ) permitted normal invasive growth (Fig. 1A, d). This reduced level of invasiveness was quite comparable with that of an otherwise isogenic ste7 $\Delta \mathrm{KSSI}^{+}$strain (data not shown). Thus, phosphorylation of Kssl on both T183 and Y 185 is required to rel ieve 
Unphosphorylated MAPK represses transcription

A
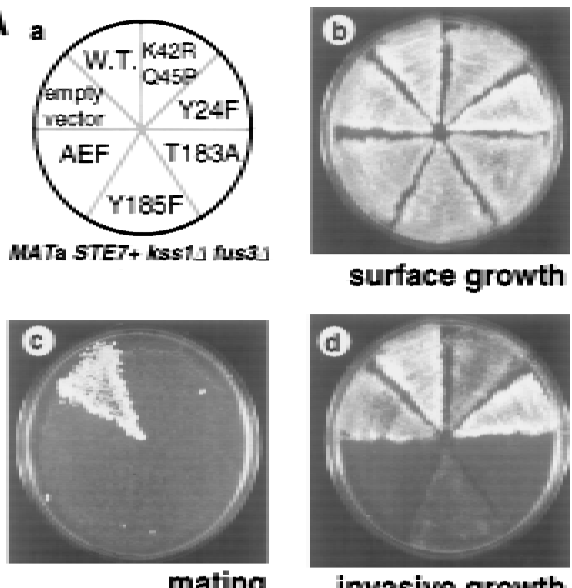

B

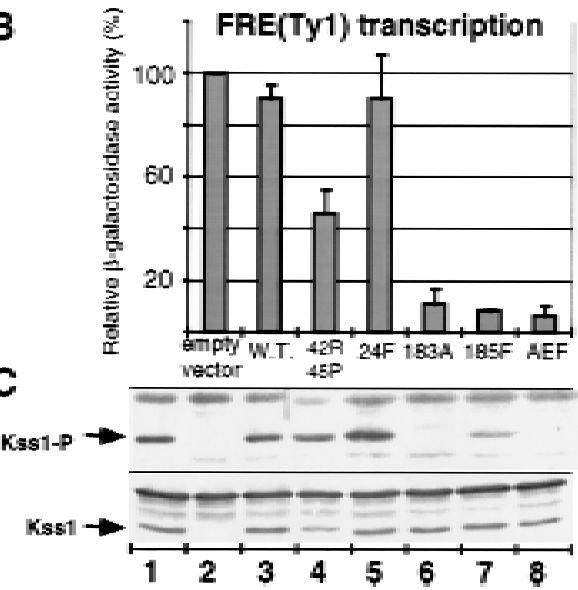

Figure 1. Phosphorylation of Kss1 is necessary and sufficient to permit haploid invasive growth. (A) Strain JCY 130 (MATa $\mathrm{STE7}^{+} \mathrm{kss} 1 \Delta$ fus3 3 ) was transformed with centromeric (lowcopy) plasmids YCpU (empty vector), YCpU-KSS1 (W.T.), YCpU-kssl(K42R Q45P), YCpU-kssl(Y24F), YCpU-kssl(T183A), YCpU-kssl(Y185F), or YCpU-kssl(AEF) (a). The resulting transformants were streaked onto a plate selective for plasmid maintenance. After 2 days at $30^{\circ} \mathrm{C}$, plates were replica-plated onto rich medium (YPD) plates and scored for surface growth (b), mating to strain DC17 (MAT $\alpha$ his1) (c), or invasive growth after $30 \mathrm{hr}$ at $30^{\circ} \mathrm{C}$ (d). (B) Expression of the $\mathrm{FRE}^{\mathrm{Ty}}{ }_{-1}$ lacZ re porter gene. The strains described in A were transformed with plasmid YEpL-FT yZ, grown to mid-log phase in liquid medium, and $\beta$-galactosidase-specific activity was measured. Values are normalized to that observed for JCY 130 carrying Y CpU (3936 $\mathrm{nmoles} / \mathrm{min}$ per milligram of protein) and represent the average of measurements, made in duplicate, on protein extracts pre pared from at least three independent transformants of each strain (error bars indicate standard deviation). (C) Portions (20 $\mu \mathrm{g}$ ) of the protein extracts used in $\mathrm{B}$, plus an additional extract (lane 1) prepared from strain JCY 100 (MATa KSS1 ${ }^{+}$), were resolved on a $10 \%$ SDS-polyacrylamide gel and analyzed by immunoblotting with either anti-Kssl (bottom) or anti-phosphoMAPK (top) antiserum.

Kss1-mediated inhibition of invasive growth. Revealingly, both of the catalytically inactive (yet phosphorylatable) mutants ( $\mathrm{KsSl}_{\mathrm{Y} 24 \mathrm{~F}}$ and $\left.\mathrm{Kssl}_{\mathrm{K} 42 \mathrm{R}} \mathrm{Q45 \textrm {P }}\right)$ permitted haploid invasi ve growth (Fig. 1A, d). Hence, phosphory-
Iation of Kssl by Ste7 suffices to relieve inhibition, even in the absence of the resultant activity of this MAPK. When Fus3 is present, however, there is a stronger requirement for the protein kinase activity of Kssl (Cook et al. 1997).

Transcription from filamentation response elements (FREs), which contain binding sites for Stel2 and Tec1 (Baur et al. 1997; Madhani and Fink 1997), correlates with M APK cascade signaling in the invasi ve growth response (Mösch et al. 1996; Madhani and Fink 1997) and reflects the degree of MAPK-mediated inhibition of invasive growth (Cook et al. 1997). Quantitative measurement of the expression of an FRE-lacZ reporter geneconfirmed the results obtained by use of the bioassay. The three unactivatable all el es permitted only minimal FREdependent transcription, whereas the two catalytically inactive alleles allowed near wild-type levels (Fig. 1B). Immunoblot analysis of protein extracts from these strains (Fig. 1C, bottom) reveal ed that each Kssl mutant (Fig. 1C, lanes 3-8) was expressed comparably with endogenous Kssl (Fig. 1C, lane 1). Staining of these same extracts with an antibody that preferentially recognizes the MEK-phosphorylated isoforms of MAPKs of the ERK (extracellular signal-regulated kinase) family, including Kss1 (see M aterials and M ethods), confirmed phosphorylation of wild-type Kssl and the catalytically inactive derivatives, and the lack (or reduction) of phosphorylation on the unactivatable Kssl mutants (Fig. 1C, top).

\section{Kss1 binds directly to Stel2}

Because inhibition of invasive growth by unphosphorylated Kssl is accompanied by repression of FRE-mediated transcription (Fig. 1B), and because Kssl is concentrated in the nucleus (Ma et al. 1995), Kssl has an opportunity to associate physically with and inhibit Stel2 and/or Tecl. Indeed, Kssl interacts with Stel2 in the two-hybrid assay (Printen and Sprague 1994; Cook et al. 1996). Moreover, Kss1- and Stel2-containing complexes (Madhani et al. 1997; L. Bardwell, unpubl.), and Fus3and Stel2-containing complexes (Elion et al. 1993; Tedford et al. 1997), have been recovered from cell extracts. However, neither of these assays demonstrates that the interaction between a MAPK and Stel2 is direct. It has been proposed (Tedford et al. 1997) that the Digl/Rst1 and Dig2/Rst2 proteins, which bind directly to both Stel2 and Kssl (Cook et al. 1996), may bridge the interaction between the MAPKs and Ste12. To determine whether Kssl can bind directly to full-length Stel2 in the absence of any other yeast protein, radiolabel ed versions of these proteins were prepared by in vitro translation in rabbit reticulocyte lysates, and their interactions were assessed by coimmunoprecipitation (Fig. 2). For this purpose, Stel2 was fused to an amino-terminal c-M yc epitope tag (see M aterial and M ethods for details). Kss1 and Stel2 were efficiently produced in radiolabeled form under the conditions used (Fig. 2, Input). As expected, tagged Ste12 was immunoprecipitated by the monoclonal antibody recognizing the c-M yc epitope (Fig. 2, Iane 8). When Kss1 and Ste12 were present in the same 


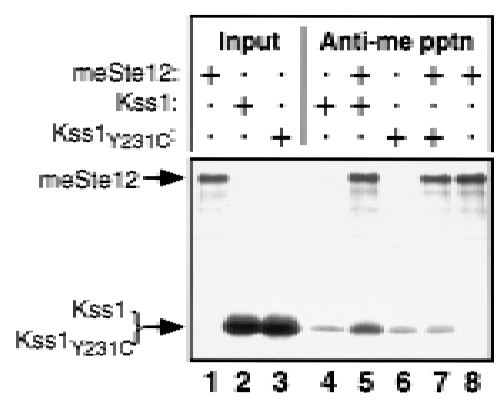

Figure2. Direct binding of Kssl to Stel2 in vitro. Radiolabeled Kss1, Kssl $1_{Y 231 c}$, and myc epitope-tagged Stel2 (meStel2) were prepared by in vitro translation, partially purified by ammonium sulfate precipitation, and portions [for Kssl and $\mathrm{Kssl}_{Y 231 c}, 5 \%$ of the amount added in the immunoprecipitation (pptn) reactions, and for meSte12, 20\%; Input] were resolved on a 10\% SDS-polyacrylamide gel. Samples (2 pmoles) of Kss1 and $\mathrm{Kss}_{231 \mathrm{C}}$, each accompanied by $\sim 200 \mu \mathrm{g}$ of total protein from the rabbit reticulocyte lysate, were immunoprecipitated with the anti-c-Myc mAb 9E10 either in the absence (lanes 4,6) or presence (lanes $5,7,8)$ of 2 pmoles meStel2 protein, and the re sulting immunopreci pitates were analyzed on the same gel. The percentage of the input Kssl derivatives bound in the reactions corresponding to lanes 4-7 was, respectively, 0.6, 1.7, 0.5, and 0.7; and of meStel2 in lanes 5,7,8: 37.2, 30.7, and 35.1.

reaction, Kssl was coimmunopreci pitated (Fig. 2, lane 5) at a level reproducibly three to fivefold above both the nonspecific association of Kssl with the antibody (Fig. 2, Iane 4) and the background displayed by $\mathrm{Kssl}_{\mathrm{Y} 231 \mathrm{C}}$, a mutant specifically defective in Stel2 binding (described in greater detail below) (Fig. 2, lanes 6,7). When determined as described (Bardwell et al. 1996), the $K_{d}$ of the Stel2-Kss1 interaction was $\sim 400 \mathrm{~nm}$. For comparison, the Ste7-Kssl interaction measured by the same methodology had a $K_{d}$ of $\sim 5 \mathrm{~nm}$ (Bardwell et al. 1996).

To delineate the Kss1-binding domain of the 688-residue Stel2 protein, we used Kss1 as bait to screen a random library and recovered seven different Stel2 isolates, including amino- and/or carboxy-terminal truncations (Cook et al. 1996). These isolates shared a common segment (residues 298-473). This portion of Stel2 lacks both the amino-terminal DNA-binding domain and the carboxy-terminal element that mediates cooperativity with the $\mathrm{Mcml}$ transcription factor, yet contains part of the transactivating region and a segment implicated in pheromone inducibility (Kirkman-Correia et al. 1993). We verified that this region of Stel2 is sufficient for MAPK association by constructing and purifying a GSTStel2 $298-473$ fusion protein, and demonstrating that this fusion (but not GST al one) specifically retains Kssl (see below; Figs. 4B and 6).

\section{Kss1 mutants specifically defective in Stel2 binding}

To provide a critical in vivo test of the importance of Kss1 association with Stel2 in the mechanism of Kss1mediated inhibition of invasive growth, we sought to generate Kssl derivatives specifically defective in binding to Stel2. Two such mutants were identified. The first derivative, $\mathrm{Kssl}_{\Delta \text { loop }}$ (Fig. 3), was constructed by site-directed mutagenesis (Bardwell et al. 1996). In

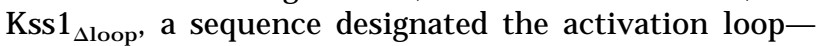
also called the activation segment (Johnson et al. 1996), phosphorylation lip (Cobb and Goldsmith 1995), or Tloop (M organ and De Bondt 1994)—has been del eted and replaced with a shorter segment from an unrelated protein kinase (yeast Tpk3). The activation loop lies along the bottom of the active site cleft in the crystal structure of unphosphorylated Erk2 (Zhang et al. 1994, 1995), and contains the target phosphoacceptor residues for MEKmediated phosphorylation (Fig. 3). In Erk2, this loop refolds upon phosphorylation, leading to activation of the enzyme (Canagarajah et al. 1997).

We isolated the second Kssl mutant using a reverse two-hybrid screen (see Materials and Methods for details). This derivative, $\mathrm{Kssl}_{\mathrm{Y} 231 \mathrm{C}}$, contains a single-residue substitution (to cysteine) at a conserved tyrosine that, in unphosphorylated Erk2 (Zhang et al. 1995), forms a hydrogen bond with the glutamate in the TEY phosphoacceptor motif (Fig. 3). Hence, al teration of this residue in $\mathrm{KSSl}_{Y 231 \mathrm{C}}$ may disrupt this hydrogen bond (and/or cause other perturbations resulting from the chemical differences between tyrosine and cysteine), thereby affecting the conformation of the activation loop region. Consistent with this conclusion, when tested in an in vitro protein kinase assay (Bardwell et al. 1996), $\mathrm{KsSl}_{Y \text { 231c }}$ was a much less efficient phosphoacceptor substrate for Ste7 than Kssl (data not shown).

The fact that the mutations in $\mathrm{Kssl}_{\Delta \text { loop }}$ and $\mathrm{Kssl}_{\mathrm{Y} 231 \mathrm{C}}$ specifically affect the ability of Kssl to interact with Stel2 was demonstrated in several ways. First, Kssl, $\mathrm{KSSl}_{\mathrm{AEF}}, \mathrm{Kssl}_{\triangle \mathrm{loop}}$ and $\mathrm{Kssl}_{Y 231 \mathrm{C}}$ were expressed as Gal4 DN A-binding domain (GDB) fusions and tested for interaction with either Ste12, Digl, or Dig2 expressed as Gal4 activation domain (GAD) fusions by use of the twohybrid method in a yeast strain containing a GAL promoter-driven reporter gene (Escherichia coli lacZ). Interaction was measured by determination of $\beta$-galactosidase-specific activity (Fig. 4A). The $\mathrm{KSSl}_{\mathrm{AEF}}, \mathrm{Kssl}_{\triangle \mathrm{Iloop}}$ and $\mathrm{KSSl}_{\mathrm{Y} 231 \mathrm{C}}$ fusions exhibited near wild-type two-hy-

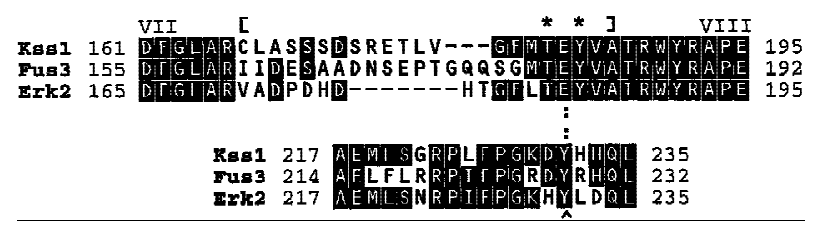

Figure 3. Structure and properties of the $\mathrm{Kssl}_{\Delta l \text { loop }}$ and $\mathrm{KsSl}_{\mathrm{Y} 231 \mathrm{C}}$ derivatives. Amino acid sequence of Kss1 and homology to yeast Fus3 and rat Erk2 in the affected regions. Dashes (-) indicate single-residue gaps; identities are boxed. In $\mathrm{Kss} 1 \Delta_{\text {Ioop }}$ protein, 21 residues of Kssl (indicated by brackets) have been replaced with the unrel ated 11-residue activation segment from S. cerevisiae T pk3 (GenBank accession no. M 17074), a homolog of the catalytic subunit of mammalian cyclic AM P-dependent protein kinase. Y231 is indicated by a carat ( ${ }^{\circ}$. The target phosphoacceptor resi dues for MEK-mediated phosphorylation are indicated by asterisks $(*)$. A hydrogen bond between $\mathrm{Y} 231$ and E184 in Erk2 is indicated by colons (:). 
A
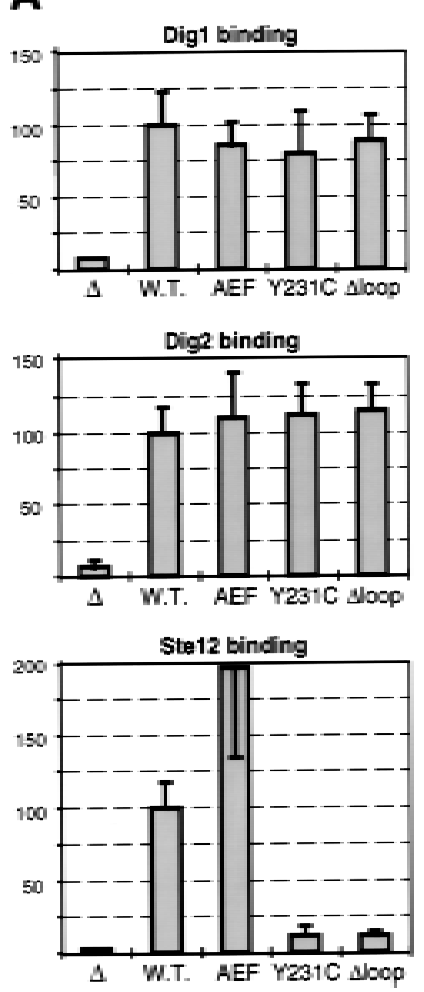

B
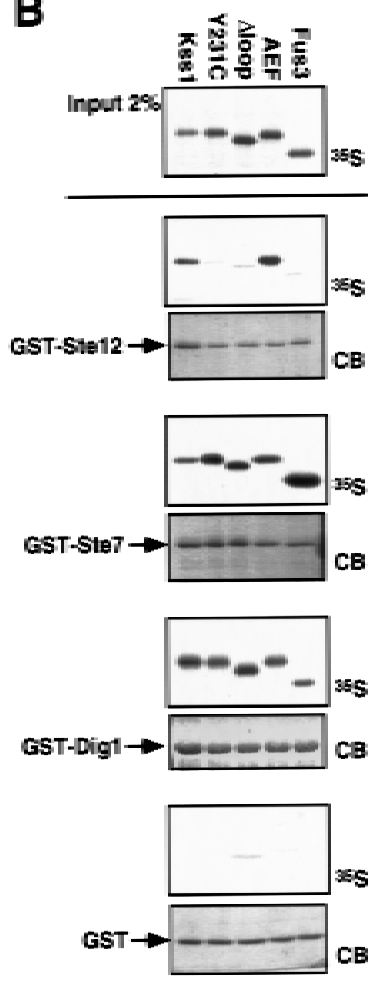

Figure 4. $K s s 1_{\Delta l o o p}$ and $K s s 1_{Y 231 C}$ are specifically defective in binding to Stel2. (A) Two-hybrid interaction of alleles of KSS1 with DIG1, DIG2, and STE12. Strain MaV103a was cotransformed with pKSS1-GDB (W.T.), pkss1(AEF)-GDB (encoding the T183A, Y 185F derivative), pkss1(Y231C)-GDB, pkss1( $\Delta$ loop)GDB, or the plasmid encoding the GDB domain only $(\Delta)$; and with pGAD-DIG1(7-452), pGAD-DIG2(56-323), or pGADSTE12(191-478); and $\beta$-gal actosi dase-specific activity was measured as described in the legend to Fig. 1B. Values are normalized to that observed for the interaction of wild-type KSS1 with DIG1, DIG2, or STE12 (41, 49 and 52 nmoles/min per milligram of protein, respectively). N one of the KSS1-GDB alleles displayed an appreciable two-hybrid interaction with an empty GAD plasmid (data not shown). (B) In vitro binding of Kssl, Kss1 mutants, and Fus3 to Ste12, Ste7, and Digl. Radiolabeled $\left({ }^{35} \mathrm{~S}\right) \mathrm{Kss1}, \mathrm{Kssl}_{\mathrm{Y} 231 \mathrm{C}}, \mathrm{Kssl}_{\Delta \mathrm{ILop}}, \mathrm{Kssl}_{\mathrm{AEF}}$, and Fus3 proteins were prepared by in vitro translation, partially purified by ammonium sulfate precipitation, and portions ( $2 \%$ of the amount added in the binding reactions; Input) were resolved on a $10 \%$ SDS-polyacrylamide gel. Samples (1 pmole) of the same proteins were incubated with $\sim 2 \mu$ of GST -Stel2 2 298-473, GST-Ste7 ${ }_{1-172}$, $\mathrm{GST} \mathrm{Digl}_{213-452}$, or GST bound to glutathione-Sepharose beads, and the resulting bead-bound protein complexes were isolated, resolved by $10 \%$ SDS-PAGE, and analyzed by staining with Coomassie blue (CB) for visualization of the bound GST fusion protein, and by autoradiography for visualization of the bound radiolabel ed $\left({ }^{35} \mathrm{~S}\right)$ protein. GST, GST $-\mathrm{Ste}_{1-172}$, and GST $\mathrm{Digl}_{213-452}$ were purified from E. coli; GST-Stel2 $298-473$ was purified from yeast (see $M$ aterials and $M$ ethods for details). The percentage of input Kssl, Kssl $1_{Y 231 C}, \mathrm{Kssl}_{\Delta l o o p}, \mathrm{Kssl}_{\mathrm{AEF}}$, and Fus3 proteins bound to GST-Stel2 was, respectively: 1.6, 0.1, $0.1,2.2$, and 0.1 ; to GST-Ste7: 8.3, 13.6, 4.4, 6.1, and 30.4; to GST-Digl: $9.1,7.8,7.4,7.2$, and 5.1; and to GST: 0.1 for all five proteins.

brid interactions with Digl and Dig2 fusions. In contrast, the $\mathrm{Kssl}_{\Delta \text { loop }}$ and $\mathrm{Kssl}_{Y \text { 231C }}$ fusions showed a severely reduced two-hybrid interaction ( $8 \%$ of wild type) with the Stel2 fusion, whereas the $\mathrm{KSSl}_{\mathrm{AEF}}$ fusion reproducibly displayed an enhanced interaction relative to wild type.

To confirm these binding properties, Kss1, Kss1 ${ }_{Y 231 C}$, $\mathrm{KSSl}_{\Delta \text { loop }}, \mathrm{KSSl}_{\mathrm{AEF}}$, as well as Fus3, were radiolabeled by translation in vitro in rabbit reticulocyte lysate, and tested for binding to purified GST-Stel2 $298-473$, GSTSte7 $_{1-172}$, GST-Digl $213-452$, or GST alone. KsS1 and $\mathrm{KSSl}_{\mathrm{AEF}}$ bound specifically to GST-Stel2 (but not to GST), whereas $\mathrm{KSSl}_{\mathrm{Y} 231 \mathrm{C}}$ and $\mathrm{KSSI}_{\Delta \text { loop }}$ did not bind to GST -Stel2 at a level above background binding to GST (Fig. 4B). In contrast, all four of the Kssl derivatives bound with approximatel y equal efficiency to both GST Ste7 and GST-Digl at a level well above nonspecific binding to GST (Fig. 4B). Fus3 did not bind detectably to purified GST-Ste12 $298-473$ in this assay, although it bound with about the same efficiency as Kssl to GST$\mathrm{Digl}_{213-452}$, and bound with greater efficiency than Kss1 to GST-Ste7 ${ }_{1-172}$ (Fig. 4B). Compared with Kss1, Fus3 also exhibited a weaker association with Stel2 in yeast cell extracts (data not shown).

Finally, as judged by coimmunoprecipitation, radiolabeled $\mathrm{Kssl}_{\mathrm{Y} 231 \mathrm{C}}$ (Fig. 2) and $\mathrm{Kssl}_{\Delta \text { loop }}$ (data not shown) were unable to interact detectably with full-length, epitope-tagged and radiol abeled Stel2.

\section{Binding of Kss1 to Stel2 is required for Kss1} to inhibit Ste12

Having demonstrated that $\mathrm{Kssl}_{\Delta \text { loop }}$ and $\mathrm{Kssl}_{Y 231 \mathrm{C}}$ are specifically defective in binding to Stel2 (but fully able to interact with Ste7, Digl, and Dig2) al lowed us to assess whether direct association between Kssl and Stel2 is involved in Kssl-mediated inhibition of invasive growth. For this purpose, alleles of KSSI (Fig. 5A, a) carried on low copy (CEN) plasmids were introduced into a hapl oid strain JCY 137 (ste7 $\Delta$ kss1 $\Delta$ fus3 $\Delta$ ). In this strain, even normal Kss1 remains unphosphorylated as a result of the absence of Ste7. Hence, wild-type, catalytically inactive and unactivatable Kssl derivatives all behaved as potent inhibitors of invasive growth (Fig. 5A, C) and of FRE-mediated transcription (Fig. 5B). In marked contrast, both $\mathrm{Kss}_{\Delta \text { loop }}$ and $\mathrm{Kss} 1_{Y 231 \mathrm{C}}$ permitted a substantial degree of invasive growth (Fig. 5A, c) and a measurably elevated level of FRE-mediated transcription (Fig. 5B). All of these Kssl derivatives were produced at about the same level as endogenous Kssl (Fig. 5C).

When introduced into a ste $\Delta / \mathrm{ste} 7 \Delta \mathrm{kss} 1 \Delta / \mathrm{kss} 1 \Delta$ diploid strain, wild-type KSS1, as well as the catalytically inactive (Y24F) and unactivatable (AEF) alleles potently inhi bi ted formati on of filaments (pseudohyphae), whereas the $Y 231 C$ and $\Delta$ loop al leles permitted at least some filamentation (data not shown). These findings suggest that Kssl binding to Stel2 mediates Kssl-imposed inhibition of invasive growth in diploids, as in haploids. However, in diploids expressing $\mathrm{Kssl}_{\mathrm{Y} 24 \mathrm{~F}}$, reintroduction of Ste7 only weakly stimulated filamentation (data not shown). 

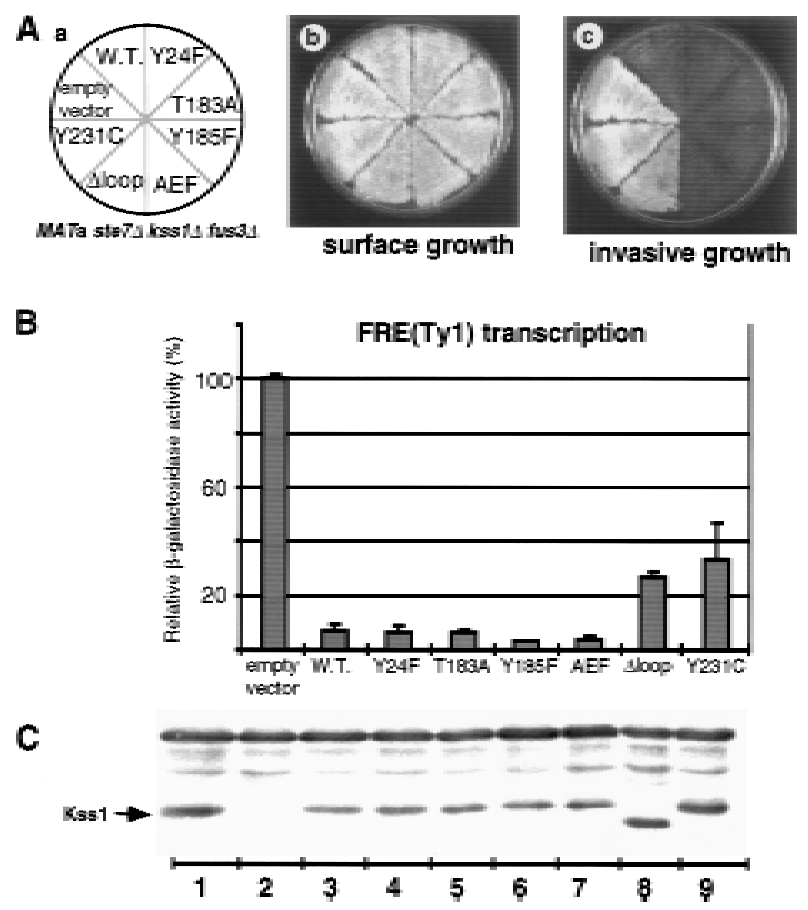

Figure 5. Stel2 binding contributes to Kssl-mediated inhibition of invasive growth. (A) Strain JCY 137 (MATa ste7 $\Delta$ kss1 $\Delta$ fus3 $\Delta$ ) was transformed with plasmid $Y C p U$ (empty vector), YCpU-KSS1 (W.T.), YCpU-kss1(Y24F), YCpU-kss1(T183A), YCpU-kssl(Y185F), YCpU-kssl(AEF), YCpU-kssl( $\Delta$ loop), or $Y C p U-k s s 1(Y 231 C)$ (a). The resulting transformants were streaked onto a plate sel ective for plasmid maintenance. After 2 days at $30^{\circ} \mathrm{C}$, plates were replica-plated onto rich medium (YPD) plates and scored for surface growth (b), or invasive growth after $30 \mathrm{hr}$ at $30^{\circ} \mathrm{C}$ (c). (B) Expression of the $F R E^{T y 1}-l a c Z$ reporter gene. The strains described in A were transformed with plasmid YEpL-FTyZ, grown to mid-exponential phase in liquid medium, and $\beta$-galactosidase specific activity was measured as detailed in the legend to Fig. 1 . Values are normalized to that observed for JCY 137 carrying Y CpU (3450 nmoles/min per milligram of protein). (C) Portions $(20 \mu \mathrm{g})$ of the protein extracts used in B, plus an additional extract (lane 1) prepared from strain JCY 100 (MATa KSS1 ${ }^{+}$), were resolved on a 10\% SDS-polyacrylamide gel and analyzed by immunoblotting with anti-Kssl antiserum.

Because $\mathrm{Kssl}_{\mathrm{Y24F}}$ is phosphorylatable, but nonfunctional (Ma et al. 1995), this result suggests that Kssl catalytic activity is required for efficient filamentation. $N$ onetheless, vigorous filament formation is observed in diploids when Kss1 is absent, even if Ste7 is also absent (C ook et al. 1997). A pparently, therefore, the catal ytic activity of phosphorylated Kssl is required in diploids to overcome the inhibitory function of those Kssl molecules that remain unphosphorylated.

Phosphorylation of Kssl reduces its affinity for Stel2

The preceding results provide strong support for the conclusion that direct physical interaction between Kssl and Stel2 is required for Kssl-mediated inhibition of invasive growth. Moreover, the findings presented above establish that Ste7 relieves this inhibition via phosphorylation of Kssl. These observations predict that phosphorylation of Kssl decreases its affinity for Stel2. To test this prediction, the ability of phosphorylated and unphosphorylated Kss1 to bind in vitro to Stel2 was examined.

To obtain extracts containing roughly equivalent amounts of total Kss1, but different amounts of phosphorylated Kss1, lysates were prepared from three different $\Sigma 1278 b$-derived strains: wild-type cells overproducing Kssl that contain a readily detectable level of phosphorylated Kssl (Fig. 6, lane 1); the same cells treated with $\alpha$-factor mating pheromone that contain an increased level of phosphorylated Kss1 (Fig. 6, lane 2); and, an otherwise isogenic ste7 $\Delta$ strain overexpressing Kssl from the same plasmid that contains no detectabl e phosphorylated Kss1 (Fig. 6, lane 3). Because Kss1 is overproduced, the bulk of the Kssl pool remains unphosphorylated, even in pheromone-treated cells (L. Bardwell and J.G. Cook, unpubl.). Total and phosphorylated Kss1 were detected as in Figure 1, quantitated by immunoblotting of serial dilutions of the samples, and normalized to the input level of Kssl (which was used as the standard).

As predicted, phosphorylated Kssl clearly bound less well to GST -Ste12 than the bulk unphosphorylated Kss1 (Fig. 6, lanes 7-9). The amount of unphosphorylated Kss1 bound was $25 \%$ of input, whereas only $1 \%-2 \%$ of the input phosphorylated Kssl bound. The $>10$-fold difference in relative retention between phosphorylated and unphosphorylated Kssl indicates that the phosphorylated form of Kssl must have a correspondingly weaker affinity for Stel2. This effect was specific to the Kssl-

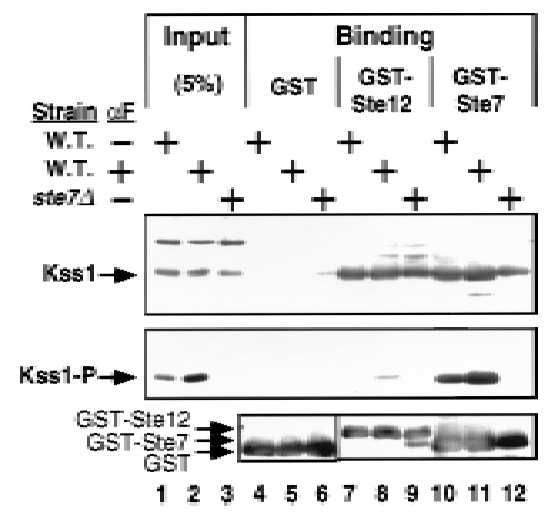

Figure 6. Phosphorylation of Kssl reduces its affinity for Ste12. Cultures of strain JCY100 (W.T.) or JCY 107 (ste74), expressing Kss1 from a multicopy plasmid (YEpT-KSS1), were grown, treated $(+)$, or not $(\rightarrow$ with $\alpha$-factor $(\alpha \mathrm{F})$ mating pheromone as indicated, and harvested. Cell extracts were prepared, and portions ( $5 \%$ of the amount added in the binding reactions; input) were resolved on a $10 \%$ SDS-polyacrylamide gel. Samples (1 mg) of the same extracts were incubated with $\sim 2 \mu \mathrm{g}$ of GST-Ste12 $298-473$, GST-Ste7 $1-172$, or GST bound to glutathione-Sepharose beads, and the resulting bead-bound protein complexes were isolated, resolved on the same gel, and analyzed by immunoblot analysis with anti-phospho-MAPK antiserum (middle) followed by stripping and reprobing with anti-Kssl (top) and anti-GST (bottom) antiserum. 
Ste12 interaction because phosphorylated and unphosphorylated Kssl associated with GST-Ste7 at the same efficiency ( $25 \%$ of input) (Fig. 6, lanes 10-12), consistent with our previous finding that Kssl-Ste7 interaction is unaffected by pheromone treatment (Bardwell et al. 1996). As expected, neither phosphorylated nor unphosphorylated Kss1 bound to GST alone (Fig. 6, lanes 4-6).

\section{Discussion}

Modulation of transcription factor function by protein kinase-mediated phosphorylation is a ubiquitous regulatory strategy. Phosphorylation-independent modes of protein kinase-mediated regulation are feasible because protein kinases often form relatively stable complexes with their substrates.

This investigation addressed two main mechanistic questions. First, how does unactivated Kss1 MAPK inhibit invasive growth? Second, how do upstream signals relieve this inhibition? We found that Kssl binds directly to the Ste12 transcription factor and thereby represses its function (Fig. 7A). Phosphorylation of the activation loop of Kss1 by the Ste7 MEK weakens Kss1Stel2 interaction, and is sufficient to relieve Kss1mediated repression (Fig. 7B). Thus, we have demonstrated that an unactivated kinase isoform po-

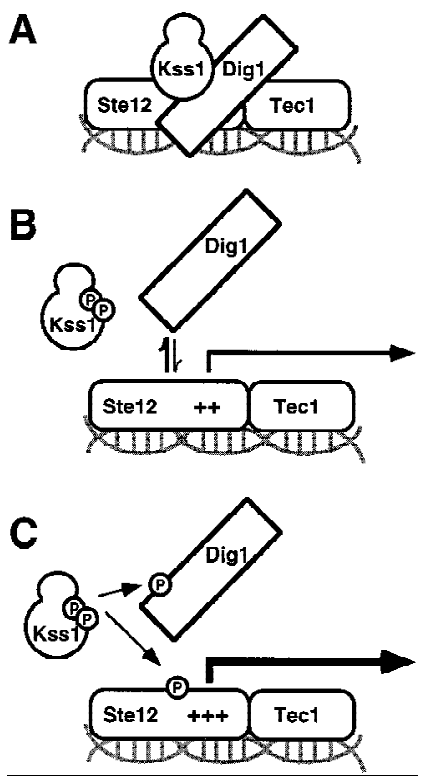

Figure 7. Model for Kssl-mediated regulation of Stel2 in invasive growth. (A) Unphosphorylated Kss1 binds directly to Ste12, and to Digl and Dig2, thereby stabilizing Digl/2-Ste12 complexes and potentiating Dig-mediated repression of Stel2. (B) Phosphorylation of Kss1 by Ste7, in response to upstream signals, causes a conformational change in Kssl that weakens its association with Ste12, and consequently reduces Digl/2 interaction with Stel2-Tec1. (C) Phosphorylated and activated Kss1 further reinforces the transition, presumably by phosphorylating Digl/2, Ste12, and/or Tec1, permitting full derepression. tently inhibits a transcription factor, and that activation of the kinase lifts this inhibition.

Two nuclear proteins-Digl and Dig2-bind to Kssl (and Fus3) and to Ste12 (Cook et al. 1996; Tedford et al. 1997). In addition, Digl and Dig2 show an interaction with Tecl in the two-hybrid assay ( $M$. Lorenz and J. Heitman, pers. comm.). Although it has been suggested that the Dig proteins bridge the interaction between the MAPKs and Ste12, we have shown here that Kss1 can bind directly to Stel2 in the absence of any other yeast proteins. M oreover, our recent results (L. Bardwell, J.G. Cook, J.X. Zhu-Shimoni and J. Thorner, in prep.) suggest that the Kss1-Stel2 interaction promotes the recruitment of Digl and Dig2, which act as negative regulators of Ste12 function (Cook et al. 1996; Tedford et al. 1997), because, for example, Kss1-mediated repression is defective in the absence of Digl and Dig2. Hence, the Dig proteins may constitute (or attract) factors that di rectly block Stel2 (and/or Tec1) action, whereas Kssl serves primarily to stabilize the Dig-Ste12-Tecl complex (Fig. 7A).

It seems likely, therefore, that phosphorylation of Kssl relieves repression by a dual mechanism. First, as we have demonstrated, phosphorylation of Kss1 by Ste7 weakens Kss1-Stel2 interaction and presumably, therefore, weakens Dig binding to (or Dig action on) Stel2 and/or Tec1 (Fig. 7B). Second, derepression of Stel2 may be further reinforced by phosphorylation of Stel2, Tecl, and/or Digl/Dig2 by activated Kssl (Fig. 7C). Phosphorylation of these proteins may further weaken these complexes and promote interaction of Ste12/Tecl with the transcription machinery. It has been shown that both Stel2 and Digl can be phosphorylated in a Kssl-dependent manner in immune complexes (Cook et al. 1996; Madhani et al. 1997) and that both GST-Ste12 $298-473$ (containing the Kssl-binding site) and GST-Digl $1_{213-452}$ (containing the Kssl- and Stel2-binding sites) serve as efficient in vitro substrates for purified Kssl (L. Bardwell, unpubl.). In fact, Kssl catalytic activity is required for optimal invasive growth in haploids, in which repression by Fus3 must also be prevented, and for efficient filamentous growth in diploids, in which the ratio of unphosphorylated Kss1 (and the Digl and Dig2 proteins) to Stel2 is perhaps higher than in haploids because of the reduced expression of STE12 in diploids (Fields and Herskowitz 1987). In toto, these events provide a switch-like mechanism to achieve commitment to a differentiated state.

Stel2 is the target of Kssl-mediated inhibition of invasive growth

The conclusion that Stel2 is the direct target of Kss1mediated inhibition of invasive growth is supported by multiple observations. First, both here and elsewhere (Cook et al. 1997), we found a remarkable correlation between the extent of inhibition caused by alleles of Kss1 (and by Fus3) and the level of expression of a Ste12dependent reporter gene (FRE ${ }^{\top y 1}-$ lacZ). Second, as weand others have found, Kssl associates with Stel2 in cell extracts (Madhani et al. 1997) and in the two-hybrid as- 
say (Printen and Sprague 1994; Cook et al. 1996). This interaction is direct because, as we showed here, Kss1 and Stel2 translated in vitro can associate. Third, Kss1 mutants specifically deficient in binding to Stel2 that we generated exhibited greatly reduced inhibition of invasive growth and FRE-mediated transcription in vivo. In a complementary approach, Madhani et al . (1997) isolated Kss1 mutants that displayed hyperfilamentation and found that some were defective in formation of Stel2-containing complexes. [Because, under some in vitro conditions, association of Kssl with Stel2 is dependent on the presence of the Dig proteins (T edford et al. 1997; Mike Tyers, pers. comm.), the alleles identified by Madhani et al. (1997) could be defective in Kss1-Dig binding, rather than in Kssl-Stel2 binding per se, or both.] Fourth, we found that Fus3, which is a weaker inhibitor of invasive growth than Kssl (Cook et al. 1997), displays a correspondingly weaker binding to Stel2. Fifth, Ste7-mediated phosphorylation of Kss1 on T183 and $Y 185$ was both necessary and sufficient to prevent Kssl-mediated inhibition and, correspondingly, reduced the affinity of Kss1 for Stel2.

Phosphorylated Kssl exhibits substantially reduced, yet still detectable, affinity for Stel2. The residual binding of activated Kss1 to Stel2 may expedite Kss1-mediated phosphorylation of Ste12, Tec1, and/or Digl and Dig2. Such a docking function has been suggested for the Ste7-Kss1, Jnk-Jun, and Erk-Elk interactions (Bardwell and Thorner 1996; Bardwell et al. 1996; Kallunki et al. 1996; Yang et al. 1998).

The activation Ioop of Kssl controls Stel2 binding and inhibition

The activation loop of M APKs is flexible, and its conformati on dictates catal ytic activity and contributes to substrate recognition (Cobb and Goldsmith 1995). Our results indicate that this segment of Kssl controls its ability to repress Stel2. Binding of unphosphorylated Kss1 to Stel2 requires integrity of the activation loop. The $\mathrm{Kssl}_{\Delta \text { loop }}$ mutant, in which this segment was removed and replaced with an unrel ated sequence, exhibited substantially reduced binding to Stel2 (but undiminished binding to Digl, Dig2, and Ste7) and correspondingly, reduced ability to repress Stel2. A substitution (Y231C) in a resi due that is conserved in most MAPKs caused the same reduction in specific binding and repression. This residue contacts the activation loop in unphosphorylated Erk2; but in phosphorylated Erk2, this contact has been broken (Zhang et al. 1995; Canagarajah et al. 1997).

The activation loop of rat Erk2 refolds foll owing M EKmediated phosphorylation (Canagarajah et al. 1997). Thus, Ste7-mediated phosphorylation of the activation Ioop of Kssl provides a simple mechanism to relieve Kssl-imposed repression. We demonstrated here that phosphorylation of T 183 and Y 185 in Kssl is necessary for Ste7 to relieve Kss1-mediated inhibition of invasive growth in vivo, and weakens Kssl-Stel2 binding in vitro. This dual phosphorylation is sufficient to relieve Kssl-mediated inhibition of haploid invasive growth, even when Kssl is not catalytically active. Thus, residues in the activation loop of Kssl may be in direct contact with Ste12. However, in Erk2, the state of the activation loop affects the conformation of the active site, the $P+1$ specificity pocket, the extended carboxyl terminus, and the so-called MAPK insertion (Zhang et al. 1995; Canagarajah et al. 1997). Hence, other regions of Kss1 could participate in Stel2 recognition. In this regard, two of the mutations (D249G and E260G) isolated by Madhani et al . (1997) are located in the MAPK insertion region.

Phosphorylation-induced refolding of an activation segment situated between conserved subdomains VII and VIII causes conformational changes required for catalysis and for access of substrates to the active site in many protein kinases (Johnson et al. 1996; Canagarajah et al. 1997). Our results argue that such structural rearrangements can al so diminish the binding of a kinase to a target, with important physiological consequences.

\section{Generality of MAPK-mediated inhibition}

Our work demonstrates that regulation of a transcription factor by a MAPK involves direct protein kinase-transcription factor binding (and recruitment by the bound kinase of other regulatory factors). How general is this mechanism? Relatively stable interactions between mammalian MAPKs and transcription factors have been observed (Gupta et al. 1996; Kallunki et al. 1996; Yang et al. 1998). It was proposed that binding of SAPK/Jnk may inhibit c-Jun function directly (Gupta et al. 1996), although this suggestion is at odds with some recent results (M ay et al. 1998). N onetheless, the inhibitory role of Kssl was revealed initially by use of genetic approaches that are more difficult in organisms less tractable than S. cerevisiae. It seems likely, therefore, that the mechanism characterized here will be found in other protein kinase signaling pathways that act as developmental switches, but may not have been readily discernible heretofore.

\section{Materials and methods}

Yeast strains and media

Yeast strains used in this work are shown in Table 1. Standard yeast media were prepared as described (Bardwell et al. 1996), except that, in synthetic complete medium, twice the recommended level of nutritional supplements was used.

\section{Plasmid constructions and recombinant DNA methods}

Plasmids YCpU (Cook et al. 1997) and YEpT-KSS1 (Bardwell et al. 1996) are described in the citations given. YEpU-FTyZ, containing the $F R E^{T y 1}$-lacZ reporter gene (and the U RA 3 gene) on a $2 \mu \mathrm{M}$ DN A plasmid, has been described el sewhere (Cook et al. 1997). The U RA 3 gene was excised from YEpU-FTyZ by digesting with Sse8387 I and Xmal and replaced with the LEU 2 gene on a Pstl-Xmal fragment excised from pJJ 252 (Jones and Prakash 1990), to yield YEpL-FTyZ.

To construct YCpU-KSSI, an EcoRI-Sphl fragment contain- 
Table 1. S. cerevisiae strains used in this study

\begin{tabular}{|c|c|c|}
\hline Strain & Genotype & Source or reference \\
\hline \multicolumn{3}{|c|}{$\begin{array}{l}\text { Haploid strains derived } \\
\text { from the } \Sigma 1278 b \text { lineage }\end{array}$} \\
\hline JCY 100 & MATahis3 $\Delta::$ hisG leu2 $\Delta::$ hisG trp1 $\Delta::$ hisG ura3-52 & $\begin{array}{l}\text { Cook et al. (1997) } \\
\text { Madhani and Fink (1997) }\end{array}$ \\
\hline JCY 107 & JCY 100 ste7 $4::$ ura3 & $\begin{array}{l}\text { Cook et al. (1997) } \\
\text { Madhani and Fink (1997) }\end{array}$ \\
\hline JCY 130 & JCY $100 \mathrm{kss} 1 \Delta::$ hisG fus $3 \Delta::$ TRP1 & $\begin{array}{l}\text { Cook et al. (1997) } \\
\text { Madhani and Fink (1997) }\end{array}$ \\
\hline $\begin{array}{l}\text { JCY } 137 \\
\text { Other strain }\end{array}$ & JCY 100 ste7 $\Delta::$ ura3 kss1 $\Delta::$ hisG fus3 $3::$ TRP1 & Cook et al. (1997) \\
\hline DC17 & MAT $\alpha$ hisl & J.B. Hicks (Cold Spring Harbor Laboratory) \\
\hline BJ2168 & MATa leu2 trp1 ura3-52 prb1-1112 pep4-3 prc1-407 gal2 & Jones (1991) \\
\hline MaV103a & $\begin{array}{l}\text { MATa leu2-3,112 trp1-901 his3 } 200 \text { ade2-101 gal } 4 \Delta \\
\text { gal 80 SPAL10::URA3 GAL1::lacZ GAL1::HIS3@ys2 can } 1^{\mathrm{R}} \text { cyh2 }{ }^{\mathrm{R}}\end{array}$ & Vidal et al. (1996) \\
\hline
\end{tabular}

ing KSS1 and its promoter was excised from plasmid YEp-KSS1 (Ma et al. 1995) and inserted into the corresponding sites of YCpU. YCpU-kssl(K42R Q45P), YCpU-kssl(Y24F), YCpUkss1(T183A), YCpU-kss1(Y185F), and YCpU-kss1(AEF) were constructed in a similar fashion with EcoRI-Sphl fragments excised from the corresponding Y Ep-based plasmids carrying these mutant alleles (Ma et al. 1995). Plasmid pRS316-KSS1 (gift of Doreen $\mathrm{Ma}$, this laboratory), contains KSS1 and its promoter on an EcoRI-BgllI fragment in the corresponding sites of pRS316 (Sikorski and Hieter 1989). To facilitate efficient subcloning of KSS1 alleles obtained from the reverse two-hybrid screen (see below) into this vector, the 0.96-kb BsiWI-BspEl fragment of KSS1 was replaced with oligonucleotide BXB1 (5'-CCGGAGAACCCCTTCC-3') annealed to BXB2 (5'-GTACGGAAGGGGTTCT-3'), yielding pRS316-kss1 $\triangle B X B$. YCpU$\mathrm{kssl}(\Delta \mathrm{loop})$ was generated by use of the BsiWI-BspEl fragment from YEpU-kssl( $\Delta$ loop) (Bardwell et al. 1996) to replace the oligonucleotide fragment of pRS316-kss1 $\triangle B X B$. YCpUkss1(Y231C) was generated in a similar fashion by the BsiWIBspEl fragment from pkss1(Y231C)-GDB (see below).

pKSS1-GDB (formerly pJGC2), encoding a Kss1-GDB domain fusion protein, has been described elsewhere (Cook et al. 1996). To facilitate the subcloning of other KSS1 alleles into this vector, the BsiWI-BspEl fragment of KSS1 was replaced with oligonucleotide $B X B 1$ annealed to $B X B 2$, yielding pkss1 $\triangle B X B-$ GDB. pkssl(AEF)-GDB (encoding the T183A Y 185F derivative) was generated by use of the BsiWI-BspEl fragment from YEpT183A Y185F ( $M$ a et al. 1995) to replace the oligonucleotide fragment of pkss1 $\triangle B X B-G D B$. pkssl( $\triangle$ loop)-GDB and pkss1(Y231C)-GDB were generated in a similar fashion with BsiWI-BspEl fragments from YEpU-kss1( $(\Delta \mathrm{loop}$ ) (Bardwell et al. 1996) and p141 (see Reverse two-hybrid screen, below), respectively. pGAD-DIG1(7-452), pGAD-DIG2(56-323), pGADSTE12(191-478), and pGAD-STE12(298-534) have been described elsewhere (Cook et al. 1996). To construct pEG-105, a BamHI fragment containing STE12(298-473) was excised from pGAD-STE12(298-534) and inserted into the BamHI site of pEG (KT) (Mitchell et al. 1993).

To fuse Ste12 to an amino-terminal c-Myc epitope tag, an EcoRI fragment containing the STE12 ORF was excised from plasmid pGAD-STE12 (gift of Stan Fields, University of Washington, Seattle) and inserted into the EcoRI site of pGEM 4Z9E10 (Bardwell et al. 1994a), yielding pGEM 4Z-meSTE12, in which the amino-terminal sequence is MEQKLISEEDLEFHM(epitope for MAb 9E10 underlined, native Stel2 initiator M et in boldface). pGEM 4Z-kss1(Y231C) was generated by use of the
BsiWI-BspEl fragment from pkss1(Y231C)-GDB to replace the corresponding fragment of pGEM4Z-KSS1 (Bardwell et al. 1996).

\section{Reverse two-hybrid screen}

The kss1(Y231C) allele was isolated in a reverse two-hybrid screen by essentially the method described by Vidal and colleagues (Vidal et al. 1996). Briefly, a library of mutagenized pKSS1-GDB plasmids was created (Greener et al. 1996) by growing this plasmid for $\sim 25$ generations in E. coli mutator strain XL-1 Red (Stratagene), using carbenicillin to select for the plasmid. Plasmid DNA was prepared and used to transform yeast strain MaV103a carrying plasmid pGAD-STE12(191-478). MaV103a contains three GAL promoter-driven reporter genes (URA3, HIS3, and E. coli lacZ). Transformants $(19,000)$ were screened for their ability to grow on agar medium containing $0.1 \% 5$-FOA, thus selecting for loss of URA 3 expression, and thereby for drastic reduction of the KSS1-STE12 two-hybrid interaction. The 218 colonies so obtained were then tested for those that could grow on agar medium containing $20 \mathrm{~mm} 3-$ amino-1H-1,2,4-triazole (3-AT), but not on $50 \mathrm{~mm}$ 3-AT, thus screening for clones that have diminished, but not completely abolished, HIS3 expression (and thereby a greatly reduced, but not completely null, KSS1-STE12 two-hybrid interaction). From the resulting five clones, the pKSS1-GDB plasmids were rescued, retransformed into $\mathrm{MaV} 103 \mathrm{a}$ along with pGADDIG1(7-452), and scored for lacZ expression to identify Kss1 mutants that fully retained the ability to interact with Digl. Only two plasmids (designated p141 and p242) met all three criteria. Nucleotide sequence analysis revealed that both of these plasmids (most likely siblings from the mutagenized DN A library) contained a single A-to-G transition at nucleotide 692 of the KSS1 ORF, resulting in a tyrosine-to-cysteine substitution at residue 231.

\section{Transcription and translation in vitro}

Transcription and translation reactions in vitro, and the partial purification of translation products by ammonium sulfate precipitation, were performed as described previously (Bardwell et al. 1992, 1996). Preparation of in vitro-translated Kssl, $\mathrm{KSSl}_{\Delta l \mathrm{oop}}, \mathrm{KSSl}_{\mathrm{AEF}}$, and Fus3 has been described elsewhere (Bardwell et al. 1996). The kss1(Y231C) mRN A was transcribed from plasmid pGEM 4Z-kss1(Y231C) linearized with $\mathrm{N}$ del. The meSTE12 mRNA was transcribed from plasmid pGEM4ZmeSTE12 linearized with Sall. 
GST-fusion protein production and binding assays

GST-Ste7 ${ }_{1-172}$ and GST-Digl ${ }_{213-452}$ were prepared from E. coli as described el sewhere (Bardwell et al. 1996; Cook et al. 1996). GST-Ste12 $298-473$ was expressed from plasmid pEG-105 in yeast strain BJ2168 and purified as follows: Cultures $(250 \mathrm{ml})$ were grown overnight in selective medium containing $2 \%$ gal actose and $0.2 \%$ sucrose, and harvested. Cell pellets were resuspended in buffer B (Bardwell et al. 1996) containing 5 mM dithiothreitol (DTT), and extracts were prepared as described previously (Bardwell et al. 1996). The extracts were adjusted to a final concentration of $1.5 \%$ (wt/vol) N-lauroyl-sarcosine (sarcosyl) and rocked at $4^{\circ} \mathrm{C}$ for $15 \mathrm{~min}$. Triton X-100 was then added to a final concentration of $3.0 \%(\mathrm{vol} / \mathrm{vol})$, followed by a further $15 \mathrm{~min}$ of rocking. The lysate was centrifuged for $5 \mathrm{~min}$ at $13,000 \mathrm{~g}$ at $4^{\circ} \mathrm{C}$ to remove insoluble material. To the resulting clarified extract, $0.1 \mathrm{ml}$ of a $50 \%$ slurry of glutathione-Sepharose (Pharmacia) was added, and the mixture was rotated for $1 \mathrm{hr}$ at $4^{\circ} \mathrm{C}$. The glutathione-Sepharose beads were collected, and washed thoroughly with buffer B containing $5 \mathrm{~mm}$ DTT and $0.75 \mathrm{M}$ potassium acetate, foll owed by buffer B containing $5 \mathrm{~mm}$ DTT. Bound proteins were eluted with three 10-min incubations at room temperature in $50 \mu \mathrm{l}$ of freshly prepared $10 \mathrm{~mm}$ reduced glutathione, $50 \mathrm{~mm}$ Tris- $\mathrm{HCl}(\mathrm{pH}$ 8.0). The eluate fractions were pooled $(150 \mu \mathrm{l}$ total $)$ and frozen at $-70^{\circ} \mathrm{C}$. Alternatively, fusion proteins bound to glutathione-Sepharose beads were stored on ice in buffer B containing $5 \mathrm{~mm}$ DTT and $1 \mathrm{mg} / \mathrm{ml}$ BSA until needed. GST-Stel2 $298-473$ protein purified from yeast by this method was judged to be $>90 \%$ pure by Coomassie blue staining and to be free of contaminating Digl, Dig2, Kss1, or Fus3 by immunoblotting. GST was purified from both yeast and E. coli. No difference in the binding properties of GST purified from these two sources was found.

Binding assays using GST fusions and in vitro-translated proteins were as described elsewhere (Cook et al. 1996). Binding assays using GST fusions and yeast cell extracts were performed by our published procedure for immunoprecipitation from yeast cell extracts (Bardwell et al. 1996), except that glutathioneSepharose-bound fusion proteins were used in place of Protein A/G-antibody beads, and $1 \mathrm{mg} / \mathrm{ml} \mathrm{BSA}$ and $5 \mathrm{~mm}$ DTT were present in all buffers.

\section{Other methods and reagents}

Expression of the $F E^{T y 1}$-lacZ reporter gene was determined as described el sewhere (Cook et al. 1997). The bi oassay for haploid invasive growth has been described (Roberts and Fink 1994). Growth and harvesting of yeast cultures for biochemical analysis, preparation of cell extracts, and coimmunoprecipitation assays were performed exactly as described previously (Bardwell et al. 1996). Anti-GST antisera was purchased from Santa Cruz Biotechnologies. The rabbit polyclonal antisera used for analysis of Kssl (Ma et al. 1995) has been described. Anti-phosphoMAPK antisera (Khokhlatchev et al. 1997), initially a gift of Erik Schaefer and thereafter obtained from a commercial source (anti-ACTIVE-M APK antisera; Promega), was used at a dilution of $1: 1300$ with overnight incubation at $4^{\circ} \mathrm{C}$.

\section{Acknowledgments}

We thank Brad Cairns, Bob Deschenes, Beverly Errede, Stan Fields, Gerald Fink, Ira Herskowitz, Erik Schaefer, Mike Tyers, and $\mathrm{M}$ arc Vidal for generous gifts of research materials, and al so MikeTyers and Joe Heitman for communication of unpublished results. We thank Mike Lorenz and Tom Burke, and especially the members of our own laboratory, for critical discussion. This work was supported by Special Senior Fellow Award 3754-98 from the Leukemia Society of America (to L.B.), by $\mathrm{N}$ ational Institutes of Health-N ational Cancer Institute ( $\mathrm{N} \mathrm{IH}-\mathrm{N} \mathrm{Cl}$ ) Postdoctoral Traineeship CA 09041 (to J.G.C.), by N IH-N ational Institute of General M edical Sciences (N IGMS) Predoctoral Traineeship GM 07232 (to D.M.B.), by funds from the Berkeley campus Summer Research Opportunities Program (to A.R.M.), by $\mathrm{NIH}$ research grant GM 21841 (to J.T.), and by resources provided by the Berkeley campus Cancer Research Laboratory.

The publication costs of this article were defrayed in part by payment of page charges. This article must therefore be hereby marked 'advertisement' in accordance with 18 USC section 1734 solely to indicate this fact.

\section{References}

Bardwell, L. and J. Thorner. 1996. A conserved motif at the amino termini of MEKs might mediate high-affinity interaction with the cognate MAPKs. Trends Biochem. Sci. 1: 373-374.

Bardwell, L., A.J. Cooper, and E.C. Friedberg. 1992. Stable and specific association between the yeast recombination and DN A repair proteins RAD1 and RAD10 in vitro. Mol. Cell. Biol. 12: 3041-3049.

Bardwell, A.J., L. Bardwell, N. Iyer, J.Q. Svejstrup, W.J. Feaver, R.D. Kornberg, and E.C. Friedberg. 1994a. Yeast nucleotide excision repair proteins Rad2 and Rad4 interact with RN A polymerase II basal transcription factor b (TFIIH). Mol. Cell. Biol. 14: 3569-3576.

Bardwell, L., J.G. Cook, C.J. Inouye, and J. Thorner. 1994b. Signal propagation and regulation in the mating pheromone response pathway of the yeast Saccharomyces cerevisiae. Devel. Biol. 166: 363-379.

Bardwell, L., J.G. Cook, E.C. Chang, B.R. Cairns, and J. Thorner. 1996. Signaling in the yeast pheromone response pathway: Specific and high-affinity interaction of the mitogen-activated protein (MAP) kinases Kss1 and Fus3 with the upstream MAP kinase kinase Ste7. Mol. Cell. Biol. 16: 36373650.

Baur, M., R.K. Esch, and B. Errede. 1997. Cooperative binding interactions required for function of the Tyl sterile responsive element. Mol. Cell. Biol. 17: 4330-4337.

Cairns, B.R., S.W. Ramer, and R.D. Kornberg. 1992. Order of action of components in the yeast pheromone response pathway reveal ed with a dominant al lel e of the STE11 kinase and the multiple phosphorylation of the STE7 kinase. Genes \& Dev. 6: 1305-1318.

Canagarajah, B.J., A. Khokhlatchev, M.H. Cobb, and E.J. Goldsmith. 1997. Activation mechanism of the MAP kinase ERK2 by dual phosphorylation. Cell 90: 859-869.

Chandarlapaty, S. and B. Errede. 1998. Ash1, a daughter cellspecific protein, is required for pseudohyphal growth of Saccharomyces cerevisiae. Mol. Cell. Biol. 18: 2884-2891.

Clevers, H. and M . van de Wetering. 1997. TCF/LEF factors earn their wings. Trends Genet. 13: 485-489.

Cobb, M.H. and E.J. Goldsmith. 1995. How MAP kinases are regulated. J. Biol. Chem. 270: 14843-14846.

Cook, J.G., L. Bardwell, S.J. Kron, and J. Thorner. 1996. Two novel targets of the MAP kinase Kssl are negative regulators of invasive growth in the yeast Saccharomyces cerevisiae. Genes \& Dev. 10: 2831-2848.

Cook, J.G., L. Bardwell, and J. Thorner. 1997. Inhibitory and activating functions for MAPK Kssl in the S. cerevisiae filamentous growth signaling pathway. Nature 390: 85-88.

DePinho, R. 1998. Transcriptional repression: The cancer-chromatin connection. Nature 391: 533. 
Elion, E.A., J.A. Brill, and G.R. Fink. 1991. FUS3 represses CLN 1 and CLN 2 and in concert with KSS1 promotes signal transduction. Proc. Natl. Acad. Sci. 88: 9392-9396.

Elion, E., B. Satterberg, and J. Kranz. 1993. Fus3 phosphorylates multiple components of the mating signal transduction cascade: Evidence for Ste12 and Far1. Mol. Biol. Cell 4: 495-510.

Erdman, S., L. Lin, M. M al czynski, and M. Snyder. 1998. Pheromone-regulated genes required for yeast mating differentiation. J. Cell Biol. 140: 461-483.

Errede, B., A. Gartner, Z. Zhou, K. N aysmith, and G. Ammerer. 1993. MAP kinase-related FUS3 from $S$. cerevisiae is activated by STE7 in vitro. Nature 362: 261-264.

Fields, S. and I. Herskowitz. 1987. Regulation by the yeast mating type locus of STE12, a gene required for expression of two sets of cell-type-specific genes. Mol. Cell. Biol. 7: 3818-3821.

Gavrias, V., A. Andrianopoulos, C.J. Gimeno, and W.E. Timberlake. 1996. Saccharomyces cerevisiae TEC1 is required for pseudohyphal growth. Mol. Microbiol. 19: 1255-1263.

Gimeno, C.J., P.O. Ljungdahl, C.A. Styles, and G.R. Fink. 1992. Unipolar cell divisions in the yeast S. cerevisiae lead to filamentous growth: Regulation by starvation and RAS. Cell 68: 1077-1090.

Goldman, P., V. Tran, and R. Goodman. 1997. The multifunctional role of the co-activator $\mathrm{CBP}$ in transcriptional regulation. Recent Prog. Horm. Res. 52: 103-119.

Greener, A., M. Callahan, and B. Jerpseth. 1996. An efficient random mutagenesis technique using an $\mathrm{E}$. coli mutator strain. In Methods in molecular biology (ed. M.K. Trower), pp. 375-385. Humana Press, Tolowa, NJ.

Gupta, S., T. Barrett, A.J. Whitmarsh, J. Cavanagh, H.L. Sluss, B. Derijard, and R.J. Davis. 1996. Selective interaction of JNK protein kinase isoforms with transcription factors. EMBO J. 15: $2760-2770$.

Heldin, C., K. Miyazono, and P. ten Dijke. 1997. TGF- $\beta$ signalling from cell membrane to nucleus through SMAD proteins. Nature 390: 465-471.

Hill, C.S. and R. Treisman. 1995. Transcriptional regulation by extracellular signals: Mechanisms and specificity. Cell 80: 199-211.

Hunter, T. and G.D. Plowman. 1997. The protein kinases of budding yeast: Six score and more. Trends Biochem. Sci. 22: 18-22.

Johnson, L.N., M.E.M. N oble, and D.J. Owen. 1996. Active and inactive protein kinases: Structural basis for regulation. Cell 85: 149-158.

Jones, E.W. 1991. Tackling the protease problem in yeast. Methods Enzymol. 194: 428-453.

Jones, J.S. and L. Prakash. 1990. Yeast Saccharomyces cerevisiae sel ectable markers in pU C18 polylinkers. Yeast 6: 363366.

Kallunki, T., T. Deng, M. Hibi, and M. Karin. 1996. c-Jun can recruit JNK to phosphorylate dimerization partners via specific docking interactions. Cell 87: 929-939.

Karin, M. 1994. Signal transduction from the cell surface to the nucleus through the phosphorylation of transcription factors. Curr. Opin. Cell Biol. 6: 415-424.

Khokhlatchev, A., S. Xu, J. English, P. Wu, E. Schaefer, and M.H. Cobb. 1997. Reconstitution of mitogen-activated protein kinase phosphorylation cascades in bacteria. J. Biol. Chem. 272: 11057-11062.

Kirkman-Correia, C., I.L. Stroke, and S. Fields. 1993. Functional domains of the yeast STE12 protein, a pheromone-responsive transcriptional activator. Mol. Cell. Biol. 13:37653772.

Kron, S.J., C.A. Styles, and G.R. Fink. 1994. Symmetric cell division in pseudohyphae of the yeast Saccharomyces cer- evisiae. Mol. Biol. Cell 5: 1003-1022.

Kübler, E., H.-U. Mösch, S. Rupp, and M.P. Lisanti. 1997. Gpa2p, a G-protein $\alpha$-subunit, regulates growth and pseudohyphal development in Saccharomyces cerevisiae via a cAM P-dependent mechanism. J. Biol. Chem. 272: 2032120323.

Laloux, I., E. Jacobs, and E. Dubois. 1994. Involvement of SRE element of Tyl transposon in TEC1-dependent transcriptional activation. Nucleic Acids Res. 22: 999-1005.

Leberer, E., D. Thomas, and M. Whiteway. 1997. Pheromone signalling and pol arized morphogenesis in yeast. Curr. O pin. Genet. Dev. 7: 59-66.

Liu, H., C.A. Styles, and G.R. Fink. 1993. Elements of the yeast pheromone response pathway required for filamentous growth of diploids. Science 262: 1741.

Lo, H.J., J.R. Köhler, B. DiDomenico, D. Loebenberg, A. Cacciapuoti, and G.R. Fink. 1997. N onfilamentous C. al bicans are avirulent. Cell 90: 939-949.

Lorenz, M.C. and J. Heitman. 1998. The MEP2 ammonium permease regulates pseudohyphal differentiation in Saccharomyces cerevisiae. EMBO J. 17: 1236-1247.

Ma, D., J.G. Cook, and J. Thorner. 1995. Phosphorylation and localization of Kssl, a MAP kinase of the Saccharomyces cerevisiae pheromone response pathway. Mol. Biol. Cell 6: 889-909.

Madhani, H.D. and G.R. Fink. 1997. Combinatorial control required for the specificity of yeast MAPK signaling. Science 275: 1314-1317.

Madhani, H.D., C.A. Styles, and G.R. Fink. 1997. M AP kinases with distinct inhibitory functions impart signaling specificity during yeast differentiation. Cell 91: 673-684.

May, G.H.W., M. Funk, E.J. Black, W. Clark, S. Hussain, J.R. Woodgett, and D.A.F. Gillespie. 1998. An oncogenic mutation uncouples the v-Jun oncoprotein from positive regulation by the SAPK/JNK pathway in vivo. Curr. Biol. 8: 117120.

Mitchell, D., T. M arshall, and R. Deschenes. 1993. Vectors for the inducible overexpression of glutathione S-transferase fusion proteins in yeast. Yeast 9: 715-722.

Morgan, D.O. and H.L. De Bondt. 1994. Protein kinase regulation: Insights from crystal structure analysis. Curr. Opin. Cell Biol. 6: 239-246.

Mösch, H.-U., R.L. Roberts, and G.R. Fink. 1996. Ras2 signals via the Cdc42/Ste20/mitogen-activated protein kinase module to induce filamentous growth in Saccharomyces cerevisiae. Proc. Natl. Acad. Sci. 93: 5352-5356.

Neiman, A.M. and I. Herskowitz. 1994. Reconstitution of a yeast protein kinase cascade in vitro: Activation of the yeast MEK homolog STE7 by STE11. Proc. Natl. Acad. Sci. 91: 3398-3402.

Printen, J.A. and G.F. Sprague Jr. 1994. Protein-protein interactions in the yeast pheromone response pathway: Ste5p interacts with all members of the MAP kinase cascade. Genetics 138: 609-619.

Rhodes, N., L. Connell, and B. Errede. 1990. STE11 is a protein kinase required for cell-type-specific transcription and signal transduction in yeast. Genes \& Dev. 4: 1862-1874.

Roberts, R.L. and G.R. Fink. 1994. Elements of a single MAP kinase cascade in Saccharomyces cerevisiae mediate two developmental programs in the same cell type: Mating and invasive growth. Genes \& Dev. 8: 2974-2985.

Roberts, R.L., H.-U. M ösch, and G.R. Fink. 1997. 14-3-3 proteins are essential for RAS/MAPK cascade signaling during pseudohyphal development in S. cerevisiae. Cell 89: 1055-1065.

Sikorski, R.S. and P. Hieter. 1989. A system of shuttle vectors and yeast host strains designed for efficient manipulation of 


\section{Bardwell et al.}

DNA in Saccharomyces cerevisiae. Genetics 122: 19-27.

Tedford, K., S. Kim, D. Sa, K. Stevens, and M. Tyers. 1997. Regulation of the mating pheromone and invasive growth responses in yeast by two MAP kinase substrates. Curr. Biol. 7: 228-238.

Treisman, R. 1996. Regulation of transcription by MAP kinase cascades. Curr. Opin. Cell. Biol. 8: 205-215.

Vandromme, M., C. Gautheir-Rouviere, N. Lamb, and A. Fernandez. 1996. Regulation of transcription factor localization: Fine-tuning of gene expression. Trends Biochem. Sci. 21: 5964.

Vidal, M., R. Brachmann, A. Fattaey, E. Harlow, and J. Boeke. 1996. Reverse two-hybrid and one-hybrid systems to detect dissociation of protein-protein and DNA-protein interactions. Proc. Natl. Acad. Sci. 93: 10315-10320.

Yang, S.-H., P.R. Yates, A.J. Whitmarsh, R.J. Davis, and A.D. Sharrocks. 1998. The Elk-1 ETS domain transcription factor contains a mitogen-activated protein kinase targeting motif. Mol. Cell. Biol. 18: 710-720.

Zhang, F., A. Strand, D. Robbins, M.H. Cobb, and E.J. Goldsmith. 1994. Atomic structure of the MAP kinase ERK2 at $2.3 \AA$ resolution. Nature 367: 704-711.

Zhang, J., F. Zhang, D. Ebert, M.H. Cobb, and E.J. Goldsmith. 1995. Activity of the MAP kinase ERK2 is controlled by a flexible surface loop. Structure 3: 299-307. 


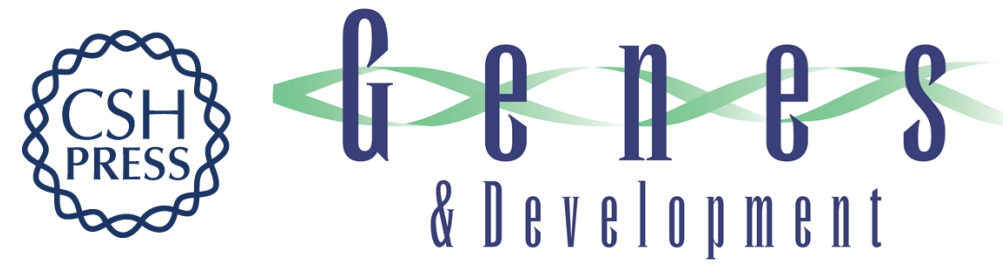

\section{Repression of yeast Ste12 transcription factor by direct binding of unphosphorylated Kss1 MAPK and its regulation by the Ste7 MEK}

Lee Bardwell, Jeanette G. Cook, Deepak Voora, et al.

Genes Dev. 1998, 12:

Access the most recent version at doi:10.1101/gad.12.18.2887

References

This article cites 57 articles, 28 of which can be accessed free at: http://genesdev.cshlp.org/content/12/18/2887.full.html\#ref-list-1

License

Email Alerting

Receive free email alerts when new articles cite this article - sign up in the box at the top Service right corner of the article or click here.

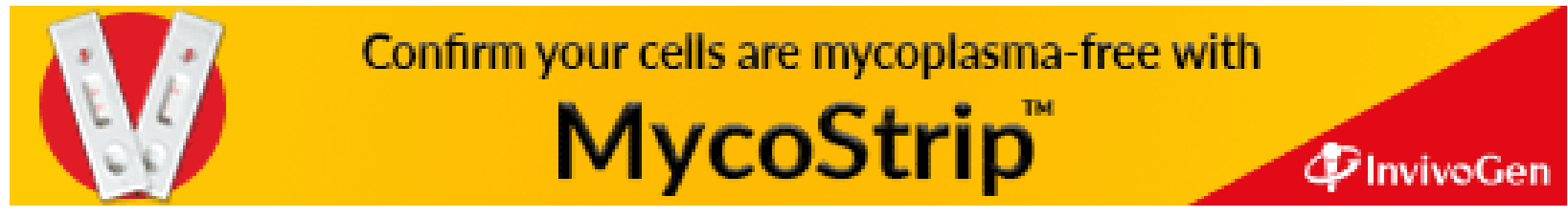

